\title{
Cognitive behavioural therapy for depression in advanced Parkinson's disease: A case illustration
}

Article in The Cognitive Behaviour Therapist · September 2012

DOI: $10.1017 /$ S1754470X12000049

CITATION

1

2 authors, including:

Thomas Richardson

Solent NHS Trust

110 PUBLICATIONS 1,725 CITATIONS

SEE PROFILE
READS

4,521

Some of the authors of this publication are also working on these related projects:

Project Test of a Cognitive Model of Cannabis related Paranoia View project

An evaluation of predictors of dropout from an Emotional Coping Skills programme in a community mental health service View project 


\section{The Cognitive Behaviour Therapist}

http://journals.cambridge.org/CBT

Additional services for The Cognitive Behaviour Therapist:

Email alerts: $\underline{\text { Click here }}$

Subscriptions: $\underline{\text { Click here }}$

Commercial reprints: Click here

Terms of use : $\underline{\text { Click here }}$

\section{Cognitive behavioural therapy for depression in advanced Parkinson's disease: a case illustration}

Thomas Richardson and Ann Marshall

The Cognitive Behaviour Therapist / Volume 5 / Issue 2-3 / September 2012, pp 60 - 69

DOI: $10.1017 / S 1754470 X 12000049$, Published online:

Link to this article: http://journals.cambridge.org/abstract_S1754470X12000049

How to cite this article:

Thomas Richardson and Ann Marshall (2012). Cognitive behavioural therapy for depression in advanced Parkinson's disease: a case illustration. The Cognitive Behaviour Therapist,5, pp 60-69 doi:10.1017/S1754470X12000049

Request Permissions : $\underline{\text { Click here }}$ 


\title{
Cognitive behavioural therapy for depression in advanced Parkinson's disease: a case illustration
}

\author{
Thomas Richardson $^{1^{*}}$ and Ann Marshall ${ }^{2}$ \\ ${ }^{1}$ Professional Training Unit, School of Psychology, University of Southampton, UK \\ ${ }^{2}$ Eastleigh Community Mental Health Team for Older People, Southern Health NHS Trust, UK
}

Received 10 February 2012; Accepted 27 June 2012; First published online 16 July 2012

\begin{abstract}
Parkinson's disease (PD) is associated with significant symptoms of depression. Cognitive behaviour therapy (CBT) has been shown to be effective for depression in PD. However, much of the previous research focuses on working with younger adults in the earlier stages of the disease, despite evidence for greater risk of depression when PD symptoms are more severe. This paper provides a case illustration of using CBT for depression with an 84-year-old man with advanced PD. The results of an assessment are described and a psychological formulation is presented. The specific adaptations made to the therapy and illustrations of the content of therapy are discussed. This intervention resulted in improvements in global mental health and moderate reductions in depression. However, there was no effect on anxiety. This case highlights the complexity of conducting CBT with this population, and further research is needed to determine the modifications necessary to make such interventions effective.
\end{abstract}

Key words: Cognitive behaviour therapy, depression, older adults, Parkinson's disease.

\section{Introduction}

Parkinson's disease (PD) is a neurodegenerative illness, with motor symptoms such as tremors, rigidity, abnormal posture and bradykinesia. The disease is, however, associated with a number of non-motor symptoms. In particular, PD has been associated with an increased risk of depression. Becker et al. (2011) estimate that in the UK, those with PD are twice as likely to have depression as those of the same age without the illness. Studies have shown that more than half of all PD patients have clinical levels of depression (Oguru et al. 2010). Cognitive behaviour therapy (CBT) with components including problem solving, behavioural activation, sleep hygiene, thought monitoring and challenging and relaxation techniques, has been shown to lead to improvements in depression, anxiety, PD symptom severity and quality of life (Cole \& Vaughan, 2005a; Dobkin et al. 2007, 2011)

Depression in this population appears to be more likely when there are impaired activities of daily living (Tandberg et al. 1997), more severe PD symptoms (Riedel et al. 2010), and pain (Ehrt et al. 2009). Thus, those who are in the more advanced stages of the illness may

\footnotetext{
*Author for correspondence: Mr T. Richardson, 34 Bassett Crescent East, Southampton, Hampshire, SO16 7PB, UK (email: thr1g10@soton.ac.uk)
} 
be in greater need of psychological interventions for depression. However, previous research has mainly been conducted with those who are younger. This group may therefore be in the early stages of PD, when physical symptoms are less severe. Dobkin et al. (2011) included those up to the age of 85 years in their trial, but the mean age was 63 years. Mohlman et al. (2010) report on the use of CBT for anxiety with someone with PD and problems with memory and attention; however, the participant was aged 74 years. Similarly Cole \& Vaughan (2005b) suggest that CBT techniques should be used to address uncertainty about prognosis, implying use with those in the early stages of disease.

Therefore whether CBT is effective with clients who are older and in the more advanced stages is unclear at present. This paper presents a case study to illustrate how CBT can be adapted for use with PD patients who are older and have more severe symptoms, and the considerations and challenges of doing so.

\section{Presenting problem}

Bob (not his real name), an 84-year-old man was referred for psychological therapy for symptoms of depression. When presenting, his mood had started to deteriorate. As a result he was lacking in motivation and not taking part in activities in his nursing home.

\section{Medical history}

Bob had experienced depression a few years previously and had an inpatient stay at the time. He had also received psychological therapy in the past which had led to improvements; however, it was concluded that his mood was likely to worsen with further physical deterioration. He had a history of strokes and right-sided hemiplegia and had limited movement in his arms and legs. Bob was diagnosed with PD 7 years earlier, and was now in the advanced stages of the disease. He had a resting tremor and limited use of his hands, with slowness of movement (bradykinesia). Bob found it hard to walk and in recent times rarely got out of his wheelchair. Rigidity also affected his facial expressions so that Bob sometimes found it hard to smile, and he often experienced freezing during movements and speech. $\mathrm{He}$ needed significant help with personal care, and was showered by staff and lifted onto the toilet using a hoist.

\section{Assessment}

The following standardized measures were used for assessment and to assess outcomes.

\section{Hospital Anxiety and Depression Scale (HADS; Zigmond \& Snaith, 1983)}

This was initially designed to assess depression and anxiety symptoms in hospital settings. It has been shown to have good psychometric properties when used to detect depression in PD (Mondolo et al. 2006).

\section{Clinical Outcomes Routine Evaluation Scale, 10-item version (CORE-10; Connell, 2007)}

This scale is used to assess global mental health in order to aid the evaluation of therapeutic work. The full version of the CORE has been shown to be reliable when used with older adults 
(Barkham et al. 2005), although the psychometric properties of the 10-item version with this age group or clinical population are unknown.

\section{Geriatric Depression Scale - Short Form (GDS-SF; Sheikh \& Yesavage, 1986)}

This scale was developed to measure depression in older adults specifically. A score of $\geqslant 5$ out of 15 has been shown to detect depression in PD with a sensitivity of 0.88 and a specificity of 0.85 (Weintraub et al. 2006).

Prior to the start of therapy Bob scored 17 on the CORE-10, which is above the clinical cut-off and within the moderate range. On the HADS Bob scored 3 for depression and 7 for anxiety which were both in the normal range. Finally he scored 8 on the GDS-SF, which was above the cut-off for depression. Bob did not report any suicidal ideation; the CORE-10 item 'I have made plans to end my life' was answered as 'Not at all'. A recent psychiatric assessment had noted no psychotic symptoms which is important as they are present in more than a quarter of PD cases (Mack et al. 2011).

\section{Cognitive functioning}

Bob had not been diagnosed with dementia or any cognitive impairment. However, his initial psychiatric assessment suggested his cognitive functioning should be assessed once his mood had improved. Moreover, cognitive impairment is common in PD (Mamikonyan et al. 2009), so is important to take this into account. However, a full neuropsychological assessment is not always needed as depression may impair cognition, thus a brief assessment of ability to engage in therapy is required (Laidlaw, 2008). The Addenbrooke's Cognitive Examination Revised (ACE-R; Mioshi et al. 2006) was used to assess Bob's cognitive functioning. This demonstrated some mild impairment on attention, concentration and memory, although the full test was not completed as Bob reported feeling too tired. However, as verbal comprehension was intact Bob was deemed able to engage in psychological therapy.

\section{Formulation}

A longitudinal formulation based on CBT was used to help plan intervention components. A simplified version of this was also developed and shown to Bob to illustrate his problem. The formulation was based on Laidlaw et al.'s (2004) conceptual framework for CBT with older people, and includes cohort beliefs, sociocultural context and roles in transition investment which were relevant in the current case. Figure 1 shows the final full formulation.

\section{Adaptations made for PD}

A CBT framework was adopted. Relevant booklets (Beck, 2000), reviews (Cole \& Vaughan, 2005b; Charidimou et al. 2011), book chapters (Laidlaw, 2008) and intervention manuals from previous research (Dobkin et al. 2011) were consulted. However, these interventions were aimed at those in the early stages of the disease, and so many of the ideas were not appropriate for Bob.

Sessions were taken at a slow pace, with only one main topic covered in a session and regular recaps and summaries. Sessions took place at the nursing home where he was resident, 


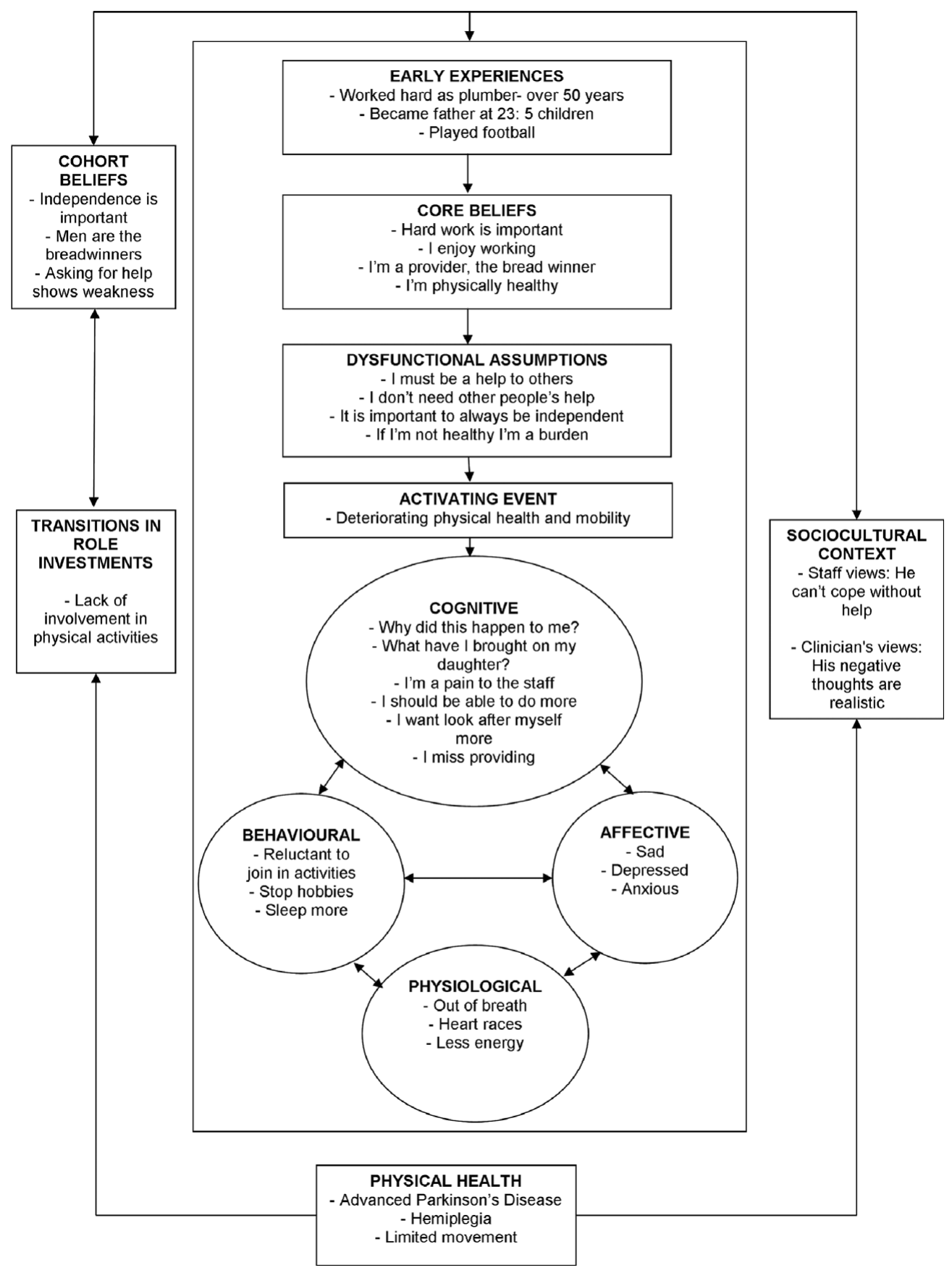

Fig. 1. Longitudinal formulation (based on Laidlaw et al. 2004). 
in the mornings when Bob reported he was most awake. Sessions were kept short at around half an hour each to avoid fatigue. Bob was encouraged to cancel or end sessions early if he did not feel well which he did so on three occasions. A total of seven sessions were conducted. Handouts were used during sessions, these were kept simple with large font text and graphics for illustration. At the end of the therapy, Bob was provided with a printed summary and poster to keep.

Previous interventions in the area (Dobkin et al. 2011) have involved patients completing worksheets. However this was not possible as Bob had limited use of his hands, so handouts were completed with him in session and then typed out. Less emphasis was placed on written homework for this reason, and because it may be more difficult for patients with PD to understand homework tasks (Charidimou et al. 2011). Bob was asked to think about or try to notice certain things over the week, rather than keeping a written record. Previous interventions have had sessions for caregivers (Dobkin et al. 2011), so nursing home staff were involved in the intervention by keeping a record of his activity participation, and being informed and encouraged to reinforce the ideas Bob had learned in therapy

\section{Intervention}

An emphasis was placed on behavioural activation in line with Bob's goals and previous trials in the area (Dobkin et al. 2007, 2011). Bob reported that he wanted to take part in activities but did not feel confident and sometimes had little motivation. The activities which Bob enjoyed in particular were discussed and this was fed back to the staff. For a number of sessions homework was set to try to record thoughts when asked to take part in an activity. The idea of anticipatory anxiety was also discussed, i.e. thinking about taking part may have been more anxiety-provoking than actually doing so. The idea of vicious cycles and a self-fulfilling prophecy was discussed in relation to this: the thought 'It's too difficult' led to emotions of feeling 'down' and 'stupid' in Bob's words, the resulting behaviour was not to take part in the activity, which then reinforced the thought that it was too hard.

Work on negative thoughts about Bob's illness focused on the meaning of his symptoms, as has been done in previous interventions (Dobkin et al. 2007, 2011). Bob was educated on the effect of thoughts on emotions and behaviour via discussion of the formulation, and also through a simplified ABC model (Situation-Thought-Result). This was applied to being helped in the shower which Bob found particularly upsetting; thinking, in Bob's words, 'I'm a bloody idiot' led to him being worried, frustrated, embarrassed and wanting to shout. Thinking instead 'It's embarrassing but it does me good' or 'It's not my fault - it's because of the PD' would lead to him feeling less worried and less embarrassed.

The idea of cognitive distortions and biases were simplified and referred to as 'thinking traps'. A handout was given which simplified these and included images for illustration. For example 'selective abstraction' was referred to as 'sad glasses'. In session these were rankordered in terms of how often Bob felt he did them, and examples were given. For example for 'mind reader', Bob's most common thinking trap, was the thought that he was a burden to the staff. For 'blaming yourself' Bob felt it was his fault when he received helped in the shower and for 'rubbishing our successes', when Bob did well in an activity, he often thought it was simply because he was lucky.

A simplified thought record was used in session to introduce how to weigh up and challenge negative thoughts. This was done for the example of being asked to take part in a game of 
Table 1. Changes in standardized measure scores

\begin{tabular}{lll}
\hline Measure & Pre-therapy score & Post-therapy score \\
\hline CORE-10 & 17 (Clinical, moderate) & 5 (Non-clinical, healthy) \\
GDS-SF & 8 (Depression) & 5 (Borderline) \\
HADS & & \\
Anxiety & 7 (Normal) & 9 (Borderline) \\
Depression & 3 (Normal) & 3 (Normal) \\
\hline
\end{tabular}

CORE-10, Clinical Outcomes Routine Evaluation Scale, 10-item version; GDS-SF, Geriatric Depression Scale - Short Form; HADS, Hospital Anxiety and Depression Scale.

skittles. The negative thought was 'It's too hard - no point trying'. Evidence for this thought was 'not much movements in hands', whereas evidence against was 'came second place in the past' and 'staff will help'. Bob then came up with an alternative thought 'It's worth a go I've done it before'. During the sessions these ideas were applied to a number of negative automatic thoughts. For example 'I miss providing for my children' was changed to 'I still provide in other ways - emotional support, being a good grandfather', and 'I'm burden to my family, I stress out my daughter' to 'My family care about me - they don't think I'm a burden'. Some simple relaxation techniques of deep breathing and guided imagery were briefly discussed with Bob. Muscle relaxation has previously been used in research in this area (Dobkin et al. 2007); however, this was not used due to Bob's physical disability.

With Bob's permission his primary nurse was seen on two occasions to inform her about the content of the sessions. Staff were encouraged to reinforce the alternative thoughts he had developed, for example when he was being helped in the shower or toilet saying to him 'I know it's embarrassing but it's for the best'. Similarly they were asked to encourage him to take part in activities by offering to help. The concept of thinking traps was introduced to staff and they were encouraged to use these ideas for example by asking him 'Are you being a mind reader?'

\section{Outcomes}

Table 1 displays the scores on the standardized measures before and after therapy. There was no change on the HADS in terms of depression, and a small increase in anxiety. There was an improvement on the GDS-SF and a substantial drop in the CORE-10. Changes on specific responses to the GDS-SF indicated that Bob no longer felt bored or that life was empty. He was also no longer afraid that something bad would happen and did not feel helpless or worried about his memory. On the CORE-10 marked changes were evident on feeling able to turn to someone for support, being better able to cope when things go wrong, and feeling less unhappy.

By the fourth session Bob reported that his mood had improved. He also reported feeling more confident and that he was now taking part in 'everything' at the home. An activities $\log$ showed that in the week after the fifth session Bob had taken part in all but one activity which was offered to him. After the final session the nurse who had been involved reported that he seemed less depressed and was much keener to take part in activities. Another nurse said they had not noticed much change but they had been away recently. The nurse who had 
been involved believed Bob was more confident and was speaking more - he had spoken in a recent residents' meeting when usually he would remain quiet. Similarly Bob had started to ask for his special cutlery for meals; prior to therapy he had simply used his hands if given the wrong cutlery. The nurse also believed he was less embarrassed when being helped in the shower or toilet.

\section{Discussion}

Depression is common is PD (Becker et al. 2011), and is more likely to occur with more severe PD symptoms (Riedel et al. 2010). However, there is little research on the use of CBT in the more advanced stages of the illness. Although the duration of PD appears not to be directly related to depression severity (Riedel et al. 2010), those who have had the illness for longer are more likely to have limited physical functioning which presents a number of challenges to clinicians. The case study described here demonstrates that adaptations can be made even when there is severe physical disability. A focus on behavioural activation and challenging thoughts about what the physical symptoms mean to them as a person appears to be warranted. However, the above case study also illustrates the complexities of such an intervention, such as sessions often being cancelled, and an inability to complete handouts due to physical disability. Similarly the physical disability of the patient limited the amount of homework tasks that could be set. This might have limited the application of therapy techniques into everyday life, but the use of staff to remind him of ideas was a useful solution to this problem. Perhaps the most important consideration is that when working with a neurodegenerative condition such as PD, physical abilities are likely to decline throughout the course of therapy, which will have an impact on subsequent mood.

It is also important to note that the effects of the intervention were somewhat limited, with changes on the CORE-10 and GDS-SF, but not HADS. This highlights the differences between CBT for depression in this instance compared to randomized controlled trials which tend to use those who are younger and may therefore be in the earlier stages of the disease (Dobkin et al. 2011). The impressive improvements noted in these trials may be hard to replicate in older clients with more severe physical symptoms. However the scores on the HADS were low to begin with and therefore there was little room for change. It is possible that Bob was underreporting his symptoms on this measure, as there was a discrepancy between pre-therapy scores on the HADS Depression scale and GDS-SF. Given the rapid deterioration in his physical functioning a moderate amount of change is perhaps to be expected; at the end of therapy an additional problem arose about having to be helped to eat which was a new source of considerable anxiety. Perhaps in the advanced stages of the illness it may be more realistic for CBT to aim for minor improvements or improved quality of life, or even simply prevent further deterioration in mood in the face of increasing disability. As suggested in the formulation, many clinicians' may have the view that the clients' negative thoughts about their situation are realistic, and therefore CBT may be limited in efficacy. Clinicians' should be aware of their own attitudes towards working with clients with PD and other serious illnesses. By accounting for physical limitations adaptations can be made which can address beliefs about the implications of poor physical health, and increase the extent to which remaining physical abilities are used for meaningful occupation.

Additional questionnaires such as the PD quality of life questionnaire (Peto et al. 1998) may have been useful with the above case and a more comprehensive assessment of memory may 
have been helpful. An older adult-specific measure of anxiety such as the Geriatric Anxiety Inventory (Pachana et al. 2007) may have also been more sensitive to change. However, the HADS has a similar evidence base for use in PD compared to other measures (Leentjens et al. 2008), and this measure was used as it was a routine outcome measure for the service.

There was also no follow-up so the long-term outcomes are unknown. Although Bob had a history of strokes this was not directly considered in planning the intervention. There is little evidence at present for CBT for post-stroke depression, although tailored interventions have recently been designed (Broomfield et al. 2011). The complexity of conducting CBT in this population requires further research in order to determine its effectiveness, and to identify the specific adaptations which are required.

\section{Summary}

Depression is common in PD, but CBT needs to be adapted carefully when used with individuals in the later stages of the illness. This paper presented a case which demonstrated that although adaptations can be made, improvements in depression may be limited due to increasing physical disability in this degenerative condition.

\section{Acknowledgements}

The authors thank the nursing home staff who helped with the intervention. Thanks are also due to 'Bob' for his hard work and for giving permission for this paper to be published.

\section{Declaration of Interest}

None.

\section{Recommended follow-up reading}

Charidimou A, Seamons J, Selai C, Schrag A (2011). The role of cognitive-behavioural therapy for patients with depression in Parkinson's disease. Parkinson's Disease.

Cole K, Vaughan FL (2005). The feasibility of using cognitive behaviour therapy for depression associated with Parkinson's disease: a literature review. Parkinsonism \& Related Disorders 11, 269276.

Laidlaw K (2008). Cognitive behaviour therapy for depression in Parkinson's disease. In: Handbook of Emotional Disorders in Later Life: Assessment and Treatment (ed. K. Laidlaw and B. Knight), pp. 383-401. Oxford: Oxford University Press.

\section{References}

Barkham M, Culverwell A, Spindler K, Twigg E (2005). The CORE-OM in an older adult population: psychometric status, acceptability, and feasibility. Aging \& Mental Health 9, 235-245.

Beck JS (2000). Coping with Depression When You Have Parkinson's Disease. Philadelphia: Beck Institute for Cognitive Therapy and Research. 
Becker C, Brobert GP, Johansson S, Jick SS, Meier CR (2011). Risk of incident depression in patients with Parkinson disease in the UK. European Journal of Neurology 18, 448-453.

Broomfield NM, Laidlaw K, Hickabottom E, Murray MF, Pendrey R, Whittick JE, Gillespie DC (2011). Post-stroke depression: the case for augmented, individually tailored cognitive behavioural therapy. Clinical Psychology \& Psychotherapy 18, 202-217.

Charidimou A, Seamons J, Selai C, Schrag A (2011). The role of cognitive-behavioural therapy for patients with depression in Parkinson's disease. Parkinson's Disease, doi:10.4061/2011/737523.

Cole K, Vaughan FL (2005a). Brief cognitive behavioural therapy for depression associated with Parkinson's disease: a single case series. Behavioural and Cognitive Psychotherapy 33, 89102.

Cole K, Vaughan FL (2005b). The feasibility of using cognitive behaviour therapy for depression associated with Parkinson's disease: a literature review. Parkinsonism \& Related Disorders 11, 269276.

Connell JBM (2007). CORE-10 User Manual, Version 1.1. Rugby: CORE System Trust \& CORE Information Management Systems Ltd.

Dobkin RD, Allen LA, Menza M (2007). Cognitive-behavioral therapy for depression in Parkinson's disease: a pilot study. Movement Disorders 22, 946-952.

Dobkin RD, Menza M, Allen LA, Gara MA, Mark MH, Tiu J, Friedman J (2011). Cognitivebehavioral therapy for depression in Parkinson's disease: a randomized, controlled trial. American Journal of Psychiatry 168, 1066-1074.

Ehrt U, Larsen JP, Aarsland D (2009). Pain and its relationship to depression in Parkinson disease. American Journal of Geriatric Psychiatry 17, 269-275.

Laidlaw K (2008). Cognitive behaviour therapy for depression in Parkinson's disease. In: Handbook of Emotional Disorders in Later Life: Assessment and Treatment (ed. K. Laidlaw and B. Knight), pp. 383-401. Oxford: Oxford University Press.

Laidlaw K, Thompson LW, Gallagher-Thompson D (2004). Comprehensive conceptualization for cognitive-behavioural therapy for late life depression. Behavioural and Cognitive Psychotherapy 32, 389-399.

Leentjens AFG, Dujardin K, Marsh L, Martinez-Martin P, Richard IH, Starkstein SE, Goetz CG (2008). Anxiety rating scales in Parkinson's disease: critique and recommendations. Movement Disorders 23, 2015-2025.

Mack J, Rabins P, Anderson K, Goldstein S, Grill S, Hirsch ES, Marsh L (2011). Prevalence of psychotic symptoms in a community-based Parkinson disease sample. American Journal of Geriatric Psychiatry 20, 123-32.

Mamikonyan E, Moberj PJ, Siderow A, Duda JE, Ten Have T, Hurtig HI, Weintraub D (2009). Mild cognitive impairment is common in Parkinson's disease patients with normal Mini-Mental State Examination (MMSE) scores. Parkinsonism \& Related Disorders 15, 226-231.

Mioshi E, Dawson K, Mitchell J, Arnold R, Hodges JR (2006). The Addenbrooke's Cognitive Examination Revised (ACE-R): a brief cognitive test battery for dementia screening. International Journal of Geriatric Psychiatry 21, 1078-1085.

Mohlman J, Reel DH, Chazin D, Ong D, Georgescu B, Tiu J, Dobkin RD (2010). A novel approach to treating anxiety and enhancing executive skills in an older adult with Parkinson's disease. Clinical Case Studies 9, 74-90.

Mondolo F, Jahanshahi M, Grana A, Biasutti E, Cacciatoria E, Di Benedetto P (2006). The validity of the hospital anxiety and depression scale and the geriatric depression scale in Parkinson's disease. Behavioural Neurology 17, 109-115.

Oguru M, Tachibana H, Toda K, Okuda B, Oka N (2010). Apathy and depression in Parkinson disease. Journal of Geriatric Psychiatry and Neurology 23, 35-41.

Pachana NA, Byrne GJ, Siddle H, Koloski N, Harley E, Arnold E (2007). Development and validation of the Geriatric Anxiety Inventory. International Psychogeriatrics 19, 103-113. 
Peto V, Jenkinson C, Fitzpatrick R (1998). PDQ-39: a review of the development, validation and application of a Parkinson's disease quality of life questionnaire and its associated measures. Journal of Neurology 245, S10-S14.

Riedel O, Heuser I, Klotsche J, Dodel R, Wittchen H-U (2010). Occurrence risk and structure of depression in Parkinson disease with and without dementia: results from the GEPAD study. Journal of Geriatric Psychiatry and Neurology 23, 27-34.

Sheikh JA, Yesavage JA (1986). Geriatric depression scale (GDS): recent findings and a development of a shorter version. In: Clinical Gerontology: A Guide to Assessment and Intervention (ed. T. L. Brink). New York: Howarth Press.

Tandberg E, Larsen JP, Aarsland D, Laake K, Cummings JL (1997). Risk factors for depression in Parkinson disease. Archives of Neurology 54, 625-630.

Weintraub D, Oehlberg KA, Katz IR, Stern MB (2006). Test characteristics of the 15-item geriatric depression scale and Hamilton Depression Rating Scale in Parkinson disease. American Journal of Geriatric Psychiatry 14, 169-175.

Zigmond AS, Snaith RP (1983). The hospital anxiety and depression scale. Acta Psychiatrica Scandinavica 67, 361-370.

\section{Learning objectives}

(1) To outline the adaptations needed for using CBT with those with Parkinson's disease.

(2) To highlight the complexity of therapeutic work in those with more severe physical symptoms and disability.

(3) To discuss the goals and potential targets of CBT in Parkinson's disease. 